\title{
Establishment of reference intervals blood parameters wintering operators based measurement uncertainty
}

\author{
Kuzovyk Vyacheslav \\ Department of Biocybernetics and \\ Aerospace Medicine \\ National Aviation University \\ Kiev \\ kyzovyk@nau.edu.ua
}

\author{
Bulygina Olena \\ Department of Biocybernetics and \\ Aerospace Medicine \\ National Aviation University \\ Kiev \\ bulygina@nau.edu.ua
}

\author{
Bezvershniuk Karyna \\ Department of Biocybernetics and \\ Aerospace Medicine \\ National Aviation University \\ Kiev \\ bezvershniuk@nau.edu.ua
}

\begin{abstract}
The research of the psychophysiological state of winterers of the Antarctic station "Academician Vernadsky" was carried out in order to establish the feasibility of their subsequent stay at the station and fulfill their service tasks. Short-term stay of polar explorers under difficult conditions causes stressful effects and nonspecific adaptive reactions. Their organisms must adapt to the exposure of various extreme factors and, in the first turn, natural ones. Considering that hematopoiesis is an important mechanism on which the ultimate adaptive result depends, a study of blood parameters was performed. It has been found that there are some changes in certain blood parameters that are not relevant with the reference norms for the studied polar groups. In this connection, there is a problem in adjusting the reference intervals for them. In order to determine the reference intervals, it is necessary to take into account the uncertainty of their establishment, having previously analyzed the sources of uncertainty.
\end{abstract}

Keywords - uncertainty, blood parameters, winterers, extreme conditions, reference interval

\section{INTRODUCTION}

Among the many medical problems in the conditions of the Antarctic station, a special place is occupied by human adaptation to environmental conditions. Cold, sudden changes in atmospheric pressure, changes in the length of the day and night, geomagnetic disturbances expose the human body to stress. An important mechanism of human adaptation is blood formation. In the normal state of the body, the blood retains a relatively constant quantitative and qualitative composition. With a general tendency to preserve this constant composition, blood is one of the most sensitive systems to such changes. Under impact of various physiological conditions, pathological and climatic factors, various symptomatic changes in the composition of the blood cells occurs in the body. Impact of the cold causes shifts in the morphological composition of the blood, for example, a decrease in cell size, a slowing of ESR is observed. The overall level of body resistance changes significantly [1]. Most of the shifts in the blood system are adaptive, reflecting the peculiar impact of Antarctic conditions on the human body. Under these conditions, a pronounced unfavorable course of adaptive processes resulting a rapid depletion of the body's energy resources, as well as suppression of regenerative functions. It is important to determine whether changes in blood parameters indicate a developing pathology or characterize adaptive processes in the body.

\section{FORMULATION OF THE PROBLEM}

For making the right decisions about the state of the organism and its reserve capabilities, information is used on the deviation of the examined indicator with its reference value. Since the establishment of reference values depends on many factors, it is necessary to analyze them in order to prevent or to take into account factors that affect accuracy of the results and, consequently, the accuracy of decision taken. Within this article, it was investigated an influence of uncertainty of measurement in establishing reference intervals for analyzed blood parameters.

\section{CHARACTERISTICS OF EXPERIMENTAL RESEARCHES}

Studies of the psychophysiological state of wintering operators were carried out on the basis of the Antarctic Station named after. "Academician Vernadsky". Previously, a study of the psychophysiological status was carried out as a result of which two groups were formed which differ in duration of stay and steady adaptation capabilities. A group of operators-winterizer number 2 - have similar psychophysiological characteristics, but it is the first time to be in extreme conditions of Antarctica. Practically healthy men (n $=36$ ) who successfully fulfilled their professional duties in extreme conditions participated in the survey. The sample of the first group consisted of 20 wintering operators, and in the second - 16. The data obtained are displayed in publications $[2,3,4]$.

Measurements of informative blood parameters were performed using an automatic hematology blood analyzer in accordance with the manufacturer's instructions for use Mindray BC-5000. Measurements were taken every month during the stay of the expedition in Antarctica. The total duration of the test was several years and about 350 values were obtained for each blood parameter.

\section{FACTORS AFFECTING ANALYSIS RESULT}

For the correct usage of the results of the analysis their reasonable interpretation is a must, taking into account the influence of biochemical and physiological mechanisms. The structure or nature of the quantity being measured (analyte), distribution in the body, method of elimination, biological half-life, control mechanisms, physiological variation, etc. should be taken into account. [5].

When assessing possible deviations of results from reference values, the influence of pathological factors should be taken into account:

- increase or decrease in the supply of analyte to this bi-liquid;

- increase or decrease in the removal of the analyte from the biological fluid in which the measurement is made,

- change in the volume of distribution of the analyte;

- changes in the structure or activity of the analyte.

The information content of the results is determined by the degree of reduction in the uncertainty of the concept of 
the physiological process, the state of the organ or the organism as a whole. The main task in evaluating the results is to establish the degree of accuracy achieved distinction between the studied and compared states of the organism. This should take into account the variation of laboratory results and its types; reference intervals of analytes and the rules for their establishment.

When using the results, it should be borne in mind that their values reflect the content of the components with some uncertainty, or in other words dispersion of these valuescaused by several types of variations, which include biological, intraindividual and interindividual, preanalytical, analytical, iatrogenic [6].

In addition, the psychophysiological state of the operators depends not only on their physiological data, but also on their mental state, resistance to stress and emotional workload (for example, the ability to make decisions promptly). A characteristic feature is that during a research biological object changes individual physiological and mental parameters, and in the transition from object to object, the error varies from the interaction of the measurement instrument with the object.

Consequently, the multi-stage research, the presence of subjective factors, the impossibility of formalizing some procedures do not allow reliably assess the psychophysiological state of man. Detection of sources of uncertainty allows corrective actions to be made when organizing research, thus reducing the uncertainty of the results. In this case, only sources of uncertainty related to the measurement procedure should be included in the uncertainty of measurement. The uncertainty of pre- and post-measurements is difficult to evaluate and toprocess properly. It is advisable to minimize, where possible, the uncertainty of pre- and post-measurements by introducing standardized training procedures for researchers, personnel training, sampling, transportation, storage. Consequently, measurements should be made strictly in accordance with the relevant procedure, without errors or other technical discrepancies.

\section{REFERENCE INTERVALS AND THEIR ESTABLISHMENT}

In assessing the data obtained, the key role is played by the determination of the difference between the norm and pathology. With an obvious deviation of laboratory parameters from the values taken as normal, it is not difficult to do this. However, in the case of assessing the state of polar explorers, it is not always easy to divide the results into "normal" and "pathology", and therefore to interpret them, a comparison with the norm established for this reference group is required.

The state of the normal parameter can be characterized by reference intervals, or the dispersion of the values of the content of analytes defined in the group of reference individuals. In this case, the reference individuals are polar explorers selected on the basis of inclusion and exclusion criteria for the formation of the reference group. Reference intervals established in this group reflect group biological variation and are usually used to distinguish pathology from health status.

Reference intervals are limited by reference limits, for which, with a $95 \%$ probability, they usually take 2.5 and 97.5 percentiles. The calculation of reference intervals depends on the size of the reference group and the type of distribution of the laboratory indicator values. With a group size of less than 120 people and an abnormal distribution of laboratory parameters, a calculation is used, according to which $90 \%$ of healthy people show "normal" laboratory parameters and $10 \%$ of healthy people - "abnormal". With a group size of more than 120 people and a normal distribution of laboratory parameters, use the calculation of reference intervals in the form of Xsr $\pm 1.96 \mathrm{SD}$, according to which $95 \%$ of healthy people are found to have "normal" laboratory parameters and 5\% of healthy people are "abnormal" [7, 8, 9]. Reference limits are determined by factors of interindividual biological variation with respect to analytical $s_{a n}^{2}$ and biological $s_{b}^{2}$ variation in accordance with inequality [6]:

$$
s_{a n}^{2} / s_{b}^{2}<0,4
$$

The established reference intervals for blood parameters are assumed to be multivariate, obtained by the combined processing of several laboratory parameters in the same group under the assumption of a normal distribution of indicators. It should be noted that the use of reference intervals established on another population can lead to errors in the interpretation of research results.

To calculate the reference values (RCV) of intervals, the average of a series of observations and two points corresponding to the lower and upper deviations are found, within which the value of this parameter is found with a certain probability. The interval found, which characterizes the scattering of the desired parameter, is the uncertainty interval, which is calculated in accordance with [10]

\section{EXAMPLE OF CALCULATION OF REFERENCE INTERVAL USING THE UNCERTAINTY OF MEASUREMENTS}

Informative parameters for assessing the psychophysiological state of man are blood parameters, which are investigated using an automatic hematological blood analyzer.

The results of the measurement have numerous sources of uncertainty, some of which are inherent in the analyzer itself, and some caused by laboratory procedures and personnel.

Inherent to the analyzer:

- volumetric mechanisms, such as pipettes;

- signal detectors;

- calibration;

- drifting the tool over time;

- Determine the sample;

- Identification of the reagent.

Sources of measurement uncertainty associated with reagents:

- Calibrator values;

- the variety of reaction of the reagent;

- stability of reagents and calibrators;

- commutativity of calibrators and reference materials.

Influence on uncertainty of measurements can:

- calibration frequency of the analyzer;

- maintenance;

-lacks in education and professional training of operators;

-lack of compliance with procedures / instructions, etc; execution of manual operations, for example, pipetting $[11,12]$.

Estimated parameters are summarized in Table. 1. This table also summarizes the arithmetic mean of the parameters and standard uncertainties of type A, calculated by the formula [10]: 


$$
u_{A}\left(x_{i}\right)=\sqrt{\frac{\sum_{q=1}^{n_{i}}\left(x_{i q}-\bar{x}_{i}\right)^{2}}{n_{i}\left(n_{i}-1\right)}}
$$

TABLE I. RESULTS OF THE MIDDLE ARIFMETIC INTRODUCTION AND STANDARD UNAVAILABILITY FOR TYPE A

\begin{tabular}{|c|c|c|c|c|}
\hline \multirow{3}{*}{ Blood parameter } & \multicolumn{4}{|c|}{ Wintering operators } \\
\hline & \multicolumn{2}{|c|}{ Group №1 } & \multicolumn{2}{|c|}{ Group №22 } \\
\hline & $\bar{x}$ & $u_{A}(x)$ & $\bar{x}$ & $u_{A}(x)$ \\
\hline Leukocytes (WBC), *109/l & 6,47 & 0,71 & 5,55 & 0,33 \\
\hline Red blood cells (RBC), ${ }^{*} 1012 / 1$ & 4,98 & 0,08 & 4,56 & 0,12 \\
\hline Hemoglobin $(\mathrm{Hb}), * 1012 \mathrm{~g} / \mathrm{l}$ & 148,67 & 3,45 & 138,38 & 3,09 \\
\hline Hematocrit (HCT), \% & 43,74 & 0,95 & 40,49 & 1,37 \\
\hline Platelets (PLT), $* 109 / 1$ & 235,56 & 7,63 & 223,38 & 11,76 \\
\hline Thrombokrit (PCT), \% & 0,18 & 0,01 & 0,17 & 0,01 \\
\hline $\begin{array}{l}\text { The average volume of red blood } \\
\text { cells }(\mathrm{MCV}), \mathrm{fl}(\mu \mathrm{m} 3)\end{array}$ & 87,89 & 0,93 & 88,50 & 1,73 \\
\hline $\begin{array}{l}\text { Average content of } \mathrm{Hb} \text { in } \\
\text { erythrocyte }(\mathrm{MCH}), \mathrm{pg}\end{array}$ & 29,86 & 0,36 & 30,39 & 0,52 \\
\hline $\begin{array}{l}\text { Average concentration of } \\
\text { hemoglobin in erythrocyte } \\
\text { (MCHC), g/l }\end{array}$ & 34,01 & 0,61 & 33,69 & 0,63 \\
\hline $\begin{array}{l}\text { Diversity of erythrocytes in } \\
\text { volume (RDV), \% }\end{array}$ & 12,54 & 0,21 & 12,58 & 0,14 \\
\hline $\begin{array}{l}\text { The average platelet count } \\
\text { (MPV), fl }\end{array}$ & 7,50 & 0,22 & 7,41 & 0,18 \\
\hline $\begin{array}{l}\text { Width of platelet distribution by } \\
\text { volume (PDW), } \%\end{array}$ & 12,88 & 0,68 & 12,84 & 0,31 \\
\hline Lymphocytes (Lym), \% & 35,22 & 4,07 & 29,25 & 2,80 \\
\hline Lymphocytes (Lym),*109/л & 2,00 & 0,17 & 1,55 & 0,15 \\
\hline Monocytes (Mon), \% & 7,11 & 0,54 & 7,13 & 0,77 \\
\hline Monocytes (Mon), ${ }^{* 109 / л ~}$ & 0,36 & 0,02 & 0,33 & 0,03 \\
\hline Granulocyte (GRA),*109/л & 4,11 & 0,68 & 3,66 & 0,31 \\
\hline Neutrophils sticky nuclei, $\%$ & 3,67 & 0,86 & 2,63 & 0,73 \\
\hline Neutrophils segmental, \% & 51,33 & 4,62 & 58,50 & 3,46 \\
\hline Eosinophilia, \% & 2,67 & 0,79 & 2,50 & 0,63 \\
\hline Bilirubin total, $\mu \mathrm{mol} / 1$ & 16,07 & 1,61 & 13,98 & 1,79 \\
\hline Urea, $\mu \mathrm{mol} / 1$ & 5,04 & 0,63 & 5,65 & 0,74 \\
\hline Creatinine, $\mu \mathrm{mol} / 1$ & 79,00 & 3,26 & 81,65 & 5,18 \\
\hline ALT, Od/l & 25,20 & 2,62 & 27,00 & 8,46 \\
\hline AST, Od/l & 27,90 & 6,64 & 25,76 & 5,37 \\
\hline Cholesterol, $\mathrm{mmol} / \mathrm{l}$ & 4,83 & 0,28 & 5,95 & 0,55 \\
\hline
\end{tabular}

The standard uncertainty of type $\mathrm{B}$ is calculated according to the uniform distribution law by the formula:

$$
u_{B}\left(x_{i}\right)=\theta_{i} / \alpha_{i}
$$

Calculated values are summarized in Table. 2 The total standard uncertainty is calculated as:

$$
u_{\mathrm{c}}(x)=\sqrt{u_{A}(x)^{2}+u_{B}(x)^{2}}
$$

\begin{tabular}{|c|c|c|}
\hline \multirow{3}{*}{ Blood parameter } & \multicolumn{2}{|c|}{ Wintering operators } \\
\hline & Group №1 & Group №2 \\
\hline & $u_{c}(x)$ & $u_{c}(x)$ \\
\hline Leukocytes (WBC), *109/1 & 0,78 & 0,43 \\
\hline Red blood cells $(\mathrm{RBC}), * 1012 / 1$ & 0,26 & 0,26 \\
\hline Hemoglobin $(\mathrm{Hb}), * 1012 \mathrm{~g} / \mathrm{l}$ & 8,19 & 7,58 \\
\hline Hematocrit (HCT), \% & 2,38 & 2,45 \\
\hline Platelets (PLT), ${ }^{*} 109 / 1$ & 14,03 & 16,22 \\
\hline Thrombokrit (PCT), \% & 0,01 & 0,01 \\
\hline $\begin{array}{l}\text { The average volume of red blood cells (MCV), } \\
\mathrm{fl}(\mu \mathrm{m} 3)\end{array}$ & 5,16 & 5,40 \\
\hline $\begin{array}{c}\text { Average content of } \mathrm{Hb} \text { in erythrocyte }(\mathrm{MCH}), \\
\text { pg }\end{array}$ & 1,76 & 1,83 \\
\hline $\begin{array}{l}\text { Average concentration of hemoglobin in } \\
\text { erythrocyte (MCHC), g/l }\end{array}$ & 1,81 & 1,80 \\
\hline Diversity of erythrocytes in volume (RDV), \% & 0,66 & 0,65 \\
\hline The average platelet count (MPV), fl & 0,48 & 0,47 \\
\hline $\begin{array}{l}\text { Width of platelet distribution by volume } \\
\text { (PDW), \% }\end{array}$ & 0,94 & 0,71 \\
\hline Lymphocytes (Lym), \% & 4,43 & 3,15 \\
\hline Lymphocytes (Lym), *109/л & 0,20 & 0,17 \\
\hline Monocytes (Mon), \% & 0,65 & 0,84 \\
\hline Monocytes (Mon), ${ }^{*} 109 /$ л & 0,03 & 0,04 \\
\hline Granulocyte (GRA), ${ }^{*} 109 /$ л & 0,71 & 0,36 \\
\hline Neutrophils sticky nuclei, \% & 0,88 & 0,74 \\
\hline Neutrophils segmental, $\%$ & 5,49 & 4,84 \\
\hline Eosinophilia, \% & 0,81 & 0,64 \\
\hline Bilirubin total, $\mu \mathrm{mol} / 1$ & 1,86 & 1,96 \\
\hline Urea, $\mu \mathrm{mol} / 1$ & 0,69 & 0,81 \\
\hline
\end{tabular}

TABLE II. RESULTS OF SIMULTANEOUS STANDARD UNIQUALITY

\begin{tabular}{|c|c|c|}
\hline Creatinine, $\mu \mathrm{mol} / \mathrm{l}$ & 5,61 & 7,00 \\
\hline $\mathrm{ALT}$, Od/l & 3,00 & 8,61 \\
\hline AST, Od/l & 6,83 & 5,57 \\
\hline Cholesterol, $\mathrm{mmol} / \mathrm{l}$ & 0,39 & 0,65 \\
\hline
\end{tabular}

Extended uncertainty of $U$ is obtained by multiplying the total standard uncertainty by the coefficient of coverage $\mathrm{k}$, whose value depends on the probability. For $\mathrm{p}=0.95, \mathrm{k}=$ 2 .

Consequently, the value of the extended uncertainty for each of the parameters studied will look like:

$$
\mathrm{Y}=\bar{Y}_{ \pm \mathrm{U}} \mathrm{p}=0,95
$$

The results of measurement of parameters in the light

\begin{tabular}{|c|c|c|}
\hline \multirow{2}{*}{ Blood parameter } & \multicolumn{2}{|c|}{ Wintering operators } \\
\hline & Group №1 & Group №2 2 \\
\hline Leukocytes (WBC), *109/1 & $6,47 \pm 1,56$ & $5,55 \pm 0,86$ \\
\hline Red blood cells (RBC),*1012/l & $4,98 \pm 0,52$ & $4,56 \pm 0,51$ \\
\hline Hemoglobin $(\mathrm{Hb}),{ }^{*} 1012 \mathrm{~g} / \mathrm{l}$ & $148,67 \pm 6,39$ & $138,38 \pm 15,16$ \\
\hline Hematocrit (HCT), \% & $43,74 \pm 4,77$ & $40,49 \pm 4,89$ \\
\hline Platelets (PLT), ${ }^{*} 109 / 1$ & $235,56 \pm 28,06$ & $223,3 \pm 32,43$ \\
\hline Thrombokrit (PCT), \% & $0,18 \pm 0,02$ & $0,17 \pm 0,03$ \\
\hline $\begin{array}{l}\text { The average volume of red blood cells (MCV), } \\
\mathrm{fl}(\mu \mathrm{m} 3)\end{array}$ & $87,89 \pm 10,32$ & $88,50 \pm 10,79$ \\
\hline $\begin{array}{c}\text { Average content of } \mathrm{Hb} \text { in erythrocyte (MCH), } \\
\text { pg }\end{array}$ & $29,86 \pm 3,53$ & $30,39 \pm 3,66$ \\
\hline $\begin{array}{l}\text { Average concentration of hemoglobin in } \\
\text { erythrocyte (MCHC), g/l }\end{array}$ & $34,01 \pm 3,61$ & $33,69 \pm 3,59$ \\
\hline Diversity of erythrocytes in volume (RDV), \% & $12,54 \pm 1,32$ & $12,58 \pm 1,29$ \\
\hline The average platelet count (MPV), fl & $7,50 \pm 0,97$ & $7,41 \pm 0,93$ \\
\hline $\begin{array}{l}\text { Width of platelet distribution by volume } \\
\text { (PDW), } \%\end{array}$ & $12,88 \pm 1,87$ & $12,84 \pm 1,43$ \\
\hline Lymphocytes (Lym), \% & $35,22 \pm 8,87$ & $29,25 \pm 6,31$ \\
\hline Lymphocytes (Lym), *109/л & $2,00 \pm 0,40$ & $1,55 \pm 0,34$ \\
\hline Monocytes (Mon), \% & $7,11 \pm 1,30$ & $7,13 \pm 1,69$ \\
\hline Monocytes (Mon), ${ }^{*} 109 /$ Л & $0,36 \pm 0,05$ & $0,33 \pm 0,07$ \\
\hline Granulocyte (GRA), ${ }^{*} 109 / \pi$ & $4,11 \pm 1,42$ & $3,66 \pm 0,73$ \\
\hline Neutrophils sticky nuclei, \% & $3,67 \pm 1,76$ & $2,63 \pm 1,48$ \\
\hline Neutrophils segmental, \% & $51,33 \pm 10,99$ & $58,50 \pm 9,68$ \\
\hline Eosinophilia, \% & $2,67 \pm 1,62$ & $2,50 \pm 1,29$ \\
\hline Bilirubin total, $\mu \mathrm{mol} / 1$ & $16,07 \pm 3,72$ & $13,98 \pm 3,93$ \\
\hline Urea, $\mu \mathrm{mol} / 1$ & $5,04 \pm 1,38$ & $5,65 \pm 1,62$ \\
\hline Creatinine, $\mu \mathrm{mol} / 1$ & $79,00 \pm 11,22$ & $81,65 \pm 14,01$ \\
\hline ALT, Od/l & $25,20 \pm 6,00$ & $27,00 \pm 17,21$ \\
\hline AST, Od/l & $27,90 \pm 13,67$ & $25,76 \pm 11,14$ \\
\hline Cholesterol, $\mathrm{mmol} / \mathrm{l}$ & $4,83 \pm 0,78$ & $5,95 \pm 1,30$ \\
\hline
\end{tabular}
of expanded uncertainty are listed in Table. 3

TABLE III. EXTENDED UNCERTAINTY FOR EVALUATED PARAMETERS FOR DIFFERENT STUDIES GROUPS

When setting the reference interval, it should be guided by the calculated expanded uncertainty and the fulfillment of the requirement:

$$
U(Y) \leq k \sqrt{C V_{J}^{2}+C V_{G}^{2}}
$$

where $C V_{J}$ - coefficient of biological internal-individual variation; $C V_{G}$ - coefficient of biological interindividual (group) variation, $\mathrm{k}$ - coefficient taking into account the degree of influence of random and systematic effects in the measurement.

For minor random effects $\mathrm{k}=0,25$, which guarantees an optimal level of accuracy; at a minimum level of accuracy $\mathrm{k}=0.75$.

The value of the coefficients of the intra-individual variation and the interindividual (group) variation is inappropriate to be determined from the standard values determined by international instruments [13], but should be determined experimentally under certain conditions according to the parameters of the blood parameters of reference individuals [14].

Consequently, the result of the measurement is compared with the biological reference interval with the $x_{\text {low }}$ and $x_{\text {high }}$, values corrected for Antarctica. 
TABLE IV. EXTENSION OF UNIQUEITY AND REFERENCE VALUES FOR BLOOD PARAMETERS

\begin{tabular}{|c|c|c|c|c|}
\hline \multirow[t]{2}{*}{ Blood parameter } & \multicolumn{2}{|c|}{$\begin{array}{c}\text { Extension of } \\
\text { uniqueity for Group } \\
\text { №1 }\end{array}$} & \multicolumn{2}{|c|}{ Reference values } \\
\hline & $x_{\text {low }}$ & $x_{\text {high }}$ & $x_{\text {low }}$ & $x_{\text {high }}$ \\
\hline Leukocytes (WBC), *109/l & 4,90 & 8,03 & 4,00 & 9,00 \\
\hline $\begin{array}{l}\text { Red blood cells }(\mathrm{RBC}), \\
* 1012 / 1\end{array}$ & 4,46 & $\mathbf{5 , 5 0}$ & 4,00 & 5,10 \\
\hline Hemoglobin $(\mathrm{Hb}), * 1012 \mathrm{~g} / \mathrm{l}$ & 132,28 & 165,05 & 130,00 & 160,00 \\
\hline Hematocrit (HCT), \% & 38,98 & 48,51 & 36,00 & 52,00 \\
\hline Platelets (PLT), *109/1 & 207,49 & 263,62 & 180,00 & 320,00 \\
\hline Thrombokrit (PCT), \% & 0,16 & 0,20 & 0,15 & 0,40 \\
\hline $\begin{array}{l}\text { The average volume of red } \\
\text { blood cells }(\mathrm{MCV}), \mathrm{fl}(\mu \mathrm{m} 3)\end{array}$ & 77,57 & 98,21 & 31,00 & 94,00 \\
\hline $\begin{array}{l}\text { Average content of } \mathrm{Hb} \text { in } \\
\text { erythrocyte (MCH), pg }\end{array}$ & 26,33 & $\mathbf{3 3 , 3 8}$ & 27,0 & 31,0 \\
\hline $\begin{array}{l}\text { Average concentration of } \\
\text { hemoglobin in erythrocyte } \\
\text { (MCHC), g/l }\end{array}$ & 30,40 & 37,63 & 29,0 & 40,0 \\
\hline $\begin{array}{l}\text { Diversity of erythrocytes in } \\
\text { volume (RDV), \% }\end{array}$ & 11,22 & 13,87 & 10,0 & 20,0 \\
\hline $\begin{array}{l}\text { The average platelet count } \\
\text { (MPV), fl }\end{array}$ & 6,53 & 8,47 & 5,0 & 10,0 \\
\hline $\begin{array}{l}\text { Width of platelet distribution } \\
\text { by volume (PDW), } \%\end{array}$ & 11,01 & 14,75 & 9,0 & 20,0 \\
\hline Lymphocytes (Lym), \% & 26,35 & 44,09 & 18,0 & 40,0 \\
\hline Lymphocytes (Lym), *109/л & 1,60 & 2,40 & 1,2 & 3,0 \\
\hline Monocytes (Mon), \% & 5,81 & 8,41 & 2,0 & 9,0 \\
\hline Monocytes (Mon), ${ }^{*} 109 /$ л & 0,30 & 0,41 & 0,1 & 0,6 \\
\hline Granulocyte (GRA), ${ }^{*} 109 /$ Л & 2,69 & 5,53 & 2,0 & 9,0 \\
\hline Neutrophils sticky nuclei, $\%$ & 1,91 & 5,43 & 1,0 & 6,0 \\
\hline Neutrophils segmental, \% & 40,35 & 62,32 & 47,0 & 72,0 \\
\hline Eosinophilia, \% & 1,05 & 4,28 & 0,0 & 5,0 \\
\hline Bilirubin total, $\mu \mathrm{mol} / 1$ & 12,34 & 19,79 & 5,0 & 21,0 \\
\hline Urea, $\mu \mathrm{mol} / 1$ & 3,66 & 6,42 & 2,5 & 8,3 \\
\hline Creatinine, $\mu \mathrm{mol} / \mathrm{l}$ & 67,78 & 90,22 & 62,0 & 115,0 \\
\hline ALT, Od/l & 19,20 & 31,20 & 0,0 & 40,0 \\
\hline AST, Od/I & 14,23 & 41,57 & 0,0 & 34,0 \\
\hline Cholesterol, mmol/l & 4,04 & 5,61 & 4,0 & 7,2 \\
\hline
\end{tabular}

As a result of comparing the results of measurement of blood parameters of wintering operators such as erythrocytes, hemoglobin, average red blood cells, average content of $\mathrm{Hb}$ in erythrocyte, lymphocytes (\%), segmented neutrophils (\%), AST, it was found that their values differ from the reference values for men from 40-75 years old, established under normal conditions, according to [13], because under the influence of extreme conditions and the environment of Antarctica, the adaptation of the psychophysiological state to the new conditions and some parameters of the blood of the operator occurs in-winterers are changing. Consequently, the results should be compared with the corrected values of reference intervals, rather than attributing them to pathological. This approach will increase the reliability of decision-making on the real psychophysiological state of polar explorers.

Due to the uncertainty of the measurement, there always exists an overlap of normal and pathological values, which leads to the risk (probability) of making an erroneous decision about the conformity of the object to the established requirements on the basis of the measured value of its property [15]. The so-called zone of uncertainty arises, while the results close to the reference intervals can not be uniquely estimated as normal or pathological, therefore, the decision making is a probabilistic problem based on measuring information.

\section{CONCLUSIONS}

During the research of the psychophysiological state of winterers of the Antarctic station "Academician Vernadsky", according to the indicators of the hematopoiesis it was established that short-term stay of polar explorers under difficult conditions causes non- specific adaptive reactions. To detect and distinguish the normal state of the body from pathological need to adjust the reference intervals of blood parameters in accordance with the conditions of the Antarctic. In determining the reference intervals, uncertainty in the measurement of indicators and the ratio of individual and group variations to expanded uncertainty have been taken into account.

To form the rule for making a decision on the state of the organism of polar explorers, taking into account the uncertainty of the measurement, the probabilistic problem, which is the scientific task of future periods, should be solved.

\section{REFERENCES}

[1] OV Frolova, O. Lepunova, O. Kormina, O. Chekunova influence of duration of residence in the conditions of the Far North on the state of hematological parameters in men and women of different ages // Advances in modern science. - 2004. - № 3. - p. 40-41.URL: https://www.natural-sciences.ru/ru/article/view?id=12384

[2] Moiseienko, Ye. V., Sukhorukov, V. I., Madiar, S.-A. Y. et al. (2006). Psykhofiziolohichnyi suprovid antarktychnykh ekspedytsii [Physiological support of Antarctic expeditions]. Kyiv, 35.

[3] Kuzovyk, V. D., Bulygina, E. V., Gordeyev, A. D. (2013). Planning and implementation aspects of study of experimental psychophysiological conditions of extreme activity operators. 2013 23rd Int. Crimean Conference «Microwave \& Telecommunication Technology» (CriMiCo'2013), 9-13 September, Sevastopol, Crimea, Ukraine. Sevastopol: Veber, 1081-1082

[4] Volodarskyi, Ye. T., Bulyhina, O. V. (2012). Statistical evaluation of professional competence of operators extreme activities.// Informatsiini tekhnolohii ta kompiuterna inzheneriia,-- 2012. - № 3. C. $71-78$

[5] Tate J.R, Jonson R, Barth J. Panteghini M. Harmonization of laboratory testing - current achievements and future strategies. Clim Chim Acta (2014) p. 432

[6] GOST R 53022.3-2008. Clinical laboratory technologies. Requirements for quality of clinical laboratory tests. Part 3 . Assessment of laboratory tests clinical significance

[7] Bertholf, R. L. Statistical methods for establishing and validating reference intervals / R. L. Bertholf // Lab. Medicine. - 2006. - Vol. 37, № 5. - P. 306-310

[8] Sinclair L., Hall S., Badrick T. A survey of Australian haematology reference intervals. Pathology. 2014; 46(6): 538-43. doi: 10.1097/ PAT.0000000000000148

[9] Melzer S., Zachariae S., Bocsi J., Engel C., Loffler M., Tarnok A. Reference intervals for leukocyte subsets in adults: Results from a populationbased study using 10-color flow cytometry. Cytometry B Clin. Cytom. 2015; 88(4): 270-81. doi: 10.1002/cyto.b.21234

[10] ISO/IEC Guide 98-1:2009 1:2009 (JCGM/WG1/104) Uncertainty of measurement - Part 1: Introduction to the expression of uncertainty in measurement.

[11] ISO 15195: 2003, Laboratory medicine - Requirements for reference measurements laboratories

[12] CLSI EP28-A3. Defining, Establishing, and Verifying Reference Intervals in the Clinical Laboratory; Approved Guideline-Third Edition, Wayne, PA, 2010

[13] Ricos C, Alvarez V, Cava F, Garcia-Lario JV, Hernandez A, Jimenez CV, Minchinela J, Perich C, Simon M. "Current databases on biologic variation: pros, cons and progress." . - URL: www.westgard.com/biodatabase1.htm

[14] Horowitz, G. L. Estimating reference intervals / G.L. Horowitz // Am. J. Clin. Pathol. — 2010. - Vol. 133, № 2. - P. 175-177.

[15] E. Volodarsky, L.Kosheva, Z. Warsha, M.Klevtsova. Uncertainty of measurement and reliability of the decision making on compliance. AUTOMATION -2019:conference Progres in Automation, Robotics and Measurement Techniques. series "Advances in Intelligent Systems and Computing", Springer, v.920, - Warsaw 2019, -pp. 672-683. 